University of Nebraska - Lincoln

DigitalCommons@University of Nebraska - Lincoln

Faculty Papers and Publications in Animal

Science

Animal Science Department

2013

\title{
The effect of myostatin genotype on body temperature during extreme temperature events
}

\author{
J. T. Howard \\ University of Nebraska-Lincoln \\ Stephen D. Kachman \\ University of Nebraska-Lincoln, steve.kachman@unl.edu \\ Merlyn K. Nielsen \\ University of Nebraska-Lincoln, mnielsen1@unl.edu \\ Terry L. Mader \\ University of Nebraska-Lincoln, tmader1@unl.edu \\ Matthew L. Spangler \\ University of Nebraska-Lincoln, mspangler2@unl.edu
}

Follow this and additional works at: https://digitalcommons.unl.edu/animalscifacpub

Part of the Genetics and Genomics Commons, and the Meat Science Commons

Howard, J. T.; Kachman, Stephen D.; Nielsen, Merlyn K.; Mader, Terry L.; and Spangler, Matthew L., "The effect of myostatin genotype on body temperature during extreme temperature events" (2013). Faculty Papers and Publications in Animal Science. 800.

https://digitalcommons.unl.edu/animalscifacpub/800

This Article is brought to you for free and open access by the Animal Science Department at DigitalCommons@University of Nebraska - Lincoln. It has been accepted for inclusion in Faculty Papers and Publications in Animal Science by an authorized administrator of DigitalCommons@University of Nebraska - Lincoln. 


\title{
The effect of myostatin genotype on body temperature during extreme temperature events ${ }^{1}$
}

\author{
J. T. Howard,* S. D. Kachman, $†$ M. K. Nielsen,* T. L. Mader, and M. L. Spangler*2 \\ *Animal Science Department, University of Nebraska, Lincoln 68583; †Department of Statistics, University of Nebraska, \\ Lincoln 68583; and \$Haskell Agricultural Laboratory, Northeast Research and Extension Center, Concord, NE 68728
}

\begin{abstract}
Extreme heat and cold events can create deleterious physiological changes in cattle as they attempt to cope. The genetic background of animals can influence their response to these events. The objective of the current study was to determine the impact of myostatin genotype (MG) on body temperature during periods of heat and cold stress. Two groups of crossbred steers and heifers of unknown pedigree and breed fraction with varying percentages of Angus, Simmental, and Piedmontese were placed in a feedlot over 2 summers and 2 winters. Before arrival, animals were genotyped for the Piedmontese-derived myostatin mutation (C313Y) to determine their MG as either homozygous normal ( 0 copy; $n=84$ ), heterozygous ( 1 copy; $n=96$ ), or homozygous for inactive myostatin ( 2 copy; $n=59$ ). Hourly tympanic and vaginal temperature measurements were collected for steers and heifers, respectively, for 5 $\mathrm{d}$ during times of anticipated heat and cold stress. Mean $( \pm$ SD) ambient temperature for summer and winter stress events were $24.4( \pm 4.64)$ and $-1.80( \pm 11.71)$, respectively. A trigonometric function (sine + cosine) with periods of 12 and $24 \mathrm{~h}$ was used to describe the

diurnal cyclical pattern. Hourly body temperature was analyzed within a season, and fixed effects included MG, group, trigonometric functions nested within group, and interaction of MG with trigonometric functions nested within group; random effects were animal and residual (Model [I]). A combined analysis of season and group was also investigated with the inclusion of season as a main effect and the nesting of effects within both group and season (Model [C]). In both models, the residual was fitted using an autoregressive covariance structure. A 3-way interaction of $\mathrm{MG}$, season, and trigonometric function periodicities of $24 \mathrm{~h}(P<0.001)$ and $12 \mathrm{~h}$ $(P<0.02)$ for Model $[\mathrm{C}]$ indicate that a genotype $\times$ environment interaction exists for MG. For MG during summer stress events the additive estimate was $0.10^{\circ} \mathrm{C}$ $(P<0.01)$ and dominance estimate was $-0.12^{\circ} \mathrm{C}(P<$ $0.001)$. During winter stress events the additive estimate was $0.10^{\circ} \mathrm{C}(P<0.001)$ and dominance estimate was $0.054^{\circ} \mathrm{C}(P>0.05)$. The current study illustrated that a genotype $\times$ environment interaction exists for $\mathrm{MG}$ and 1-copy animals were more robust to environmental extremes in comparison with 0 - or 2-copy animals.
\end{abstract}

Key words: beef cattle, body temperature, genotype $\times$ environment interaction, myostatin

(C) 2013 American Society of Animal Science. All rights reserved.

J. Anim. Sci. 2013.91:3051-3058 doi:10.2527/jas2012-6180

\section{INTRODUCTION}

Beef animals are often managed in extensive production systems with minimal environmental modifications, making body temperature regulation an essential component to maintaining overall animal efficiency (Young, 1983; Hahn, 1999). To mitigate

\footnotetext{
${ }^{1}$ The authors thank Leslie J. Johnson, Stephanie Moore, Cody Schneider, and Brandon Nuttelman for their assistance during data collection.

${ }^{2}$ Corresponding author: mspangler2@unl.edu

Received December 13, 2012.

Accepted March 20, 2013.
}

these risks, producers currently use knowledge of average breed effects relative to heat or cold tolerance to determine which breed or breeds will perform best in a particular environment. An alternative strategy is to differentiate animals within a population based on their inherent differences for body temperature regulation. The mean core body temperature of cattle is $38.6^{\circ} \mathrm{C}$ (McDowell, 1972). Indicators of core body temperature from the mean include tympanic (Davis et al., 2003) or vaginal measurements (McGee et al., 2008). Animal variation has been shown to exist for body temperature regulation during periods of external temperature stress in beef cattle (Da Silva, 1973; Turner, 
1982, 1984; Burrow, 2001) and dairy cattle (Ravagnolo and Misztal, 2000, 2002; Dikmen et al., 2012).

Identifying interactions of genetic backgrounds or large effect mutations with production environments would allow for informed management decisions at multiple levels throughout the production chain. One such mutation is myostatin, which produces an inactive myostatin protein product causing the well-characterized "double muscling" phenotype (Kambadur et al., 1997). An animal with 2 copies of the inactive myostatin allele yields an extremely lean and heavily muscled carcass whereas an animal with 1 copy displays some increased leanness and muscularity but not to the degree as an animal with 2 copies (Short et al., 2002; Casas et al., 2004). These differences in body composition, particularly reduced fat cover in 2-copy animals, could lead to differences in sensitivity to extreme temperatures. The objectives of the current study were to determine the impact of myostatin on body temperature during periods of heat and cold stress.

\section{MATERIALS AND METHODS}

The project was approved by the University of Nebraska-Lincoln Institutional Animal Care and Use Committee.

\section{Experimental Design}

Crossbred steers and heifers of unknown pedigree and breed fractions $(n=239)$ with varying percentages of Angus, Simmental, and Piedmontese were placed in a Calan gate facility at the Agricultural Research and Development Center (ARDC) feedlot facility near Mead, NE. Before arrival, animals were genotyped for the Piedmontese-derived myostatin mutation (C313Y) to determine their myostatin genotype (MG) as either homozygous normal (0 copy; $n=84$ ), heterozygous (1 copy; $n=96$ ), or homozygous for inactive myostatin ( 2 copy; $n=59$ ). Cattle were fed in 4 groups over a 2 -yr period. Groups 1 and 3 consisted of calf-fed steers and groups 2 and 4 consisted of yearling heifers. The steer groups were on feed from Dec. 16, 2009 to June 22, 2010 (S1) and Dec. 23, 2010 to June 22, 2011 (S2). The heifer groups were on feed from July 28, 2010 to Nov. 28, 2010 (H1) and July 28, 2011 to Dec. 2, 2011 (H2). Each group was randomly allocated into 2 pens, with approximately 30 animals per pen.

Animals had ad libitum access to water and were fed a diet that met or exceeded NRC requirements (NRC, 1996). The finishing ration for $H 1$ and $S 1$ included wet distillers grain with solubles, a 1:1 blend of high moisture and dry rolled corn, grass hay, and supplement at 35, 52, 8 , and $5 \%$ of the diet, respectively. The finishing ration for $\mathrm{H} 2$ and S2 included modified distillers grain with solubles, sweet bran, a 1:1 blend of high moisture and dry rolled corn, grass hay, and supplement at 20, 20, 48, 8 , and $4 \%$ of the diet, respectively. Animals were on an all-natural program and were not implanted with nor fed growth-promoting additives. Ultrasonic rump fat, rib fat, ribeye area, and intramuscular fat percentage and BW were recorded monthly. Individual feed bunks were filled each day and refusals were calculated on average every $6 \mathrm{~d}$ with a range of 1 to $9 \mathrm{~d}$. A feeding period is described as the time between 2 successive feed refusal collections. Cattle were harvested as a group based on average BW and external fat.

During anticipated times of heat and cold stress, hourly body temperature recording devices were placed for a minimum of $5 \mathrm{~d}$ inside the ear canal (tympanic) for steers or intravaginally for heifers. Body temperature was recorded using the micro- $T$ software (Nexsens Technology, Beavercreek, $\mathrm{OH}$ ) along with the DS1921H ibutton data loggers with a resolution of $0.0625^{\circ} \mathrm{C}$ (Maxim Integrated Products, Inc., Sunnyvale, CA). Loggers were individually entered into a database and programmed to begin recording the morning after data loggers were placed in the ear. This allowed for elevated body temperature due to physical activity (i.e., going through the chute and data logger application) to be eliminated from the analysis. Additionally, animals were housed in a confined environment, and thus physical activity from walking long distances to water or feed was minimized. Increased physical activity, either through human interaction or animal necessity, has been shown by Mader et al. (2005) to increase body temperature for a short period of time, which may give false indicators of heat or cold stress. The tympanic temperature protocol included placing each logger in the finger of a latex glove and tying the logger off with the remaining portion discarded. It was then placed in the ear as far as possible along with a cone shaped foam rubber stress ball to pack the logger inside the ear to seal the logger from the external environment. Vet wrap was wrapped around the ear to hold the data logger and stress ball in place and then athletic tape was used to secure everything for the duration of the recording period. Vaginal temperature protocol used the same data logger and software device as was used for tympanic temperature. A blank (i.e., did not contain hormones) controlled internal drug release (CIDR) was modified by cutting out the center silicone section to allow for the placement of the data logger. The data logger was then sealed in the CIDR using silicone sealant and inserted into the vagina using a CIDR applicator. A subset of heifers $(n=8)$ had both tympanic and vaginal body temperature recorded and a correlation of 0.98 was estimated between the 2. Tympanic temperature 
Table 1. Average ( $( \pm \mathrm{SD})$ age, rump, rib fat, BW, DMI, and days on feed before each heat stress event by group

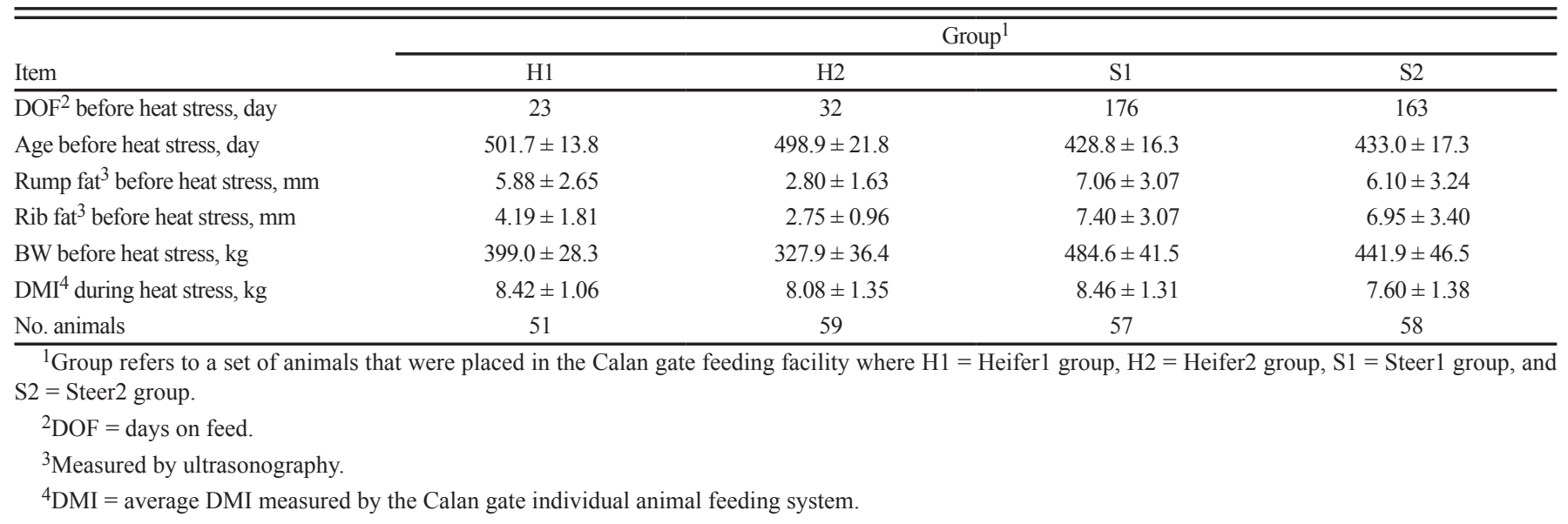

averaged $0.163^{\circ} \mathrm{C}$ greater than vaginal temperature. To account for this, steer body temperature measurements were adjusted down by 0.163 . In a study by Bergen and Kennedy (2000), the authors found a phenotypic correlation of $0.77(P<0.05)$ between vaginal and tympanic temperature in 9 crossbred heifer calves across multiple recording periods whereas in the current study the correlation was derived from a single recording period. The average $( \pm \mathrm{SD})$ age, ultrasonic rump and rib fat, BW, and DMI along with the number of days on feed before the recorded stress event by group are in Tables 1 and 2 for heat and cold stress events, respectively.

Ambient temperature $\left({ }^{\circ} \mathrm{C}\right)$, relative humidity (\%), wind speed $\left(\mathrm{km} \mathrm{h}^{-1}\right)$, and solar radiation $\left(\mathrm{kcal} \mathrm{m}^{-2}\right)$ were taken hourly at the ARDC using an automated weather station. The ARDC is located at $41^{\circ} 14^{\prime} \mathrm{N}$ latitude and $96^{\circ} 48^{\prime} \mathrm{W}$ longitude, with a mean elevation of $353 \mathrm{~m}$ above sea level. These variables were used to compute a comprehensive climate index that is effective for winter and summer conditions (Mader et al., 2010). The animals were housed in a partially enclosed cement floor barn with a flush system. The open side of the barn faced the south and led to a small dirt floored pen. Due to the type of housing, the effects of the environmental variables may not be as severe as animals on pasture or pens without access to shade or wind protection. The average $( \pm \mathrm{SD})$ environmental variables and hourly animal body temperatures along with the number of animals in the analysis and dates of the stress period by group are in Tables 3 and 4 for heat and cold stress events, respectively. Animals were removed from the analysis for summer $(n=14)$ and winter $(n=13)$ stress events due to missing hourly body temperature observations. Additional steers $(n=5)$ were removed from the analysis for winter stress events due to body temperature observations not showing a cyclical pattern similar to other animals in the group, likely due to data logger malfunctions.

\section{Statistical Analysis}

Hourly body temperature was analyzed using a trigonometric function (sine + cosine) with periods of 12 and $24 \mathrm{~h}$. The trigonometric function included covariates of sine $\left(2 \pi a / S_{m}\right)$ and cosine $\left(2 \pi a / S_{m}\right)$, in which $a$ was the hour of a day (i.e., 1 to 24 ) and $S_{m}$ denoted the

Table 2. Average ( $( \pm \mathrm{SD})$ age, rump fat, rib fat, BW, DMI, and days on feed before each cold stress event by group

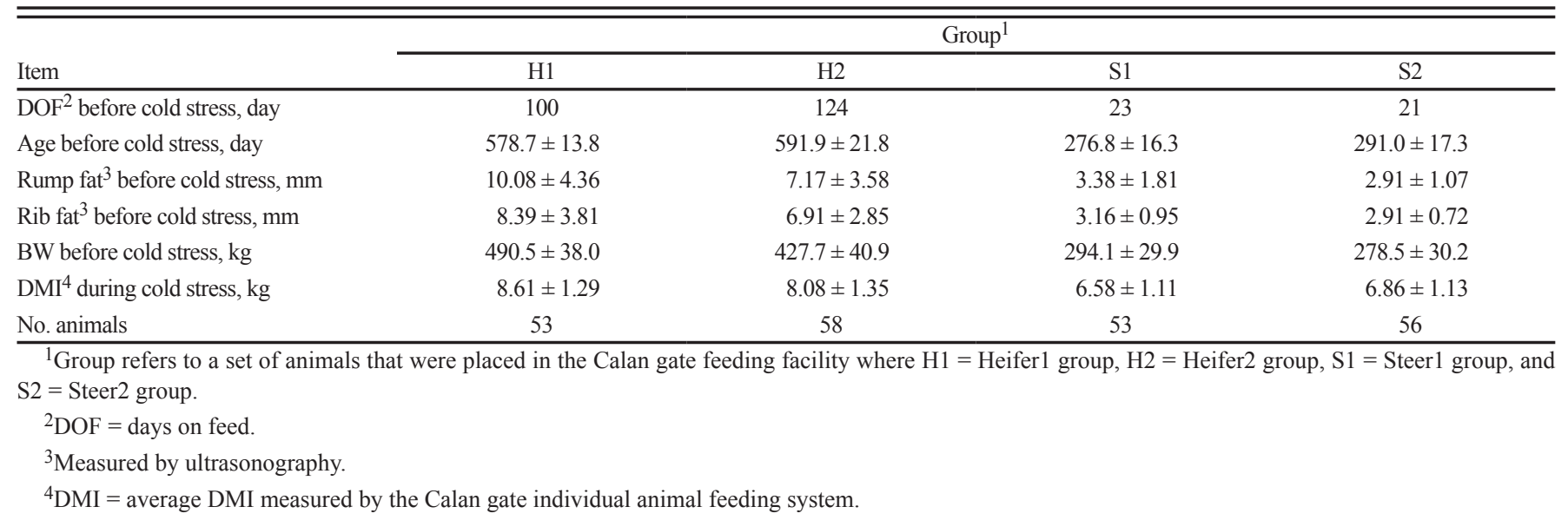


Table 3. Average $( \pm \mathrm{SD})$ environmental conditions, hourly animal body temperature, and dates for each heat stress event by group

\begin{tabular}{|c|c|c|c|c|}
\hline \multirow[b]{2}{*}{ Item } & \multicolumn{4}{|c|}{ Group $^{1}$} \\
\hline & $\mathrm{H} 1$ & $\mathrm{H} 2$ & $\mathrm{~S} 1$ & $\mathrm{~S} 2$ \\
\hline Ambient temperature ${ }^{2},{ }^{\circ} \mathrm{C}$ & $24.3( \pm 4.7)$ & $23.7( \pm 4.1)$ & $22.8( \pm 3.7)$ & $26.8( \pm 5.1)$ \\
\hline Relative humidity ${ }^{2}, \%$ & $82.2( \pm 17.1)$ & $81.7( \pm 13.1)$ & $81.5( \pm 15.3)$ & $52.7( \pm 16.3)$ \\
\hline Wind speed ${ }^{2}, \mathrm{~km} / \mathrm{h}$ & $4.0( \pm 2.1)$ & $5.4( \pm 3.0)$ & $7.4( \pm 3.2)$ & $10.1( \pm 5.0)$ \\
\hline Solar radiation ${ }^{2}, \mathrm{kcal} / \mathrm{m} 2 / \mathrm{h}$ & $213.0( \pm 261.9)$ & $189.2( \pm 233.6)$ & $195.5( \pm 264.9)$ & $242.4( \pm 279.8)$ \\
\hline $\mathrm{CCI}^{3},{ }^{\circ} \mathrm{C}$ & $28.2( \pm 6.9)$ & $26.4( \pm 5.7)$ & $23.6( \pm 6.2)$ & $25.9( \pm 6.0)$ \\
\hline
\end{tabular}

Date of heat stress

Aug. 20 to Aug. 24, $2010 \quad$ Aug. 20 to Aug. 24, $2011 \quad$ June 9 to June 13, 2010

June 4 to June 8, 2011

\footnotetext{
${ }^{1}$ Group refers to a set of animals that were placed in the Calan gate feeding facility where H1 = Heifer1 group, H2 = Heifer2 group, S1 = Steer1 group, and $\mathrm{S} 2=\mathrm{Steer} 2$ group

${ }^{2}$ Environmental parameters were taken at the Agricultural Research and Development Center using an automated weather station.

${ }^{3} \mathrm{CCI}=$ comprehensive climate index (Mader et al., 2010).

${ }^{4} \mathrm{BT}=$ body temperature.
}

length of the periodicity. Best fit trigonometric function periodicities were determined within each season by including periodicities of 1 to $24 \mathrm{~h}$ nested within group, $\mathrm{MG}$, group, and the interaction of $\mathrm{MG}$ and group as fixed effects and animal as a random effect. Trigonometric function periodicities were retained if they were significant and had a large impact, relative to other periodicities, on decreasing the residual variance. Trigonometric function periodicities of $24 \mathrm{~h}(\mathbf{2 4 H})$ and $12 \mathrm{~h}(\mathbf{1 2 H} ; P<0.05)$ were retained for winter and summer stress events.

To account for the inherent covariance structure between hourly body temperatures, the residual was fitted with a covariance pattern within animal and a covariance of 0 across animals (Kaps and Lamberson, 2004; Littell et al., 1998). Multiple covariance patterns were investigated and autoregressive 1 (AR1) was chosen based on Akaike's information criteria. The AR1 covariance pattern includes 1 covariance parameter, rho
( $\rho$ ) with the covariance decreasing exponentially as hourly body temperature observations get further away from one another. This model was used across all groups within a season:

$$
\begin{aligned}
& \mathrm{BT}_{i j l m}=\mu+M_{i}+G_{j}+M_{i} \times G_{j}+\cos 24 \mathrm{H} \times G_{j}+ \\
& \sin 24 \mathrm{H} \times G_{j}+\cos 12 \mathrm{H} \times G_{j}+\sin 12 \mathrm{H} \times G_{j}+\cos 24 \mathrm{H} \times \\
& M_{i} \times G_{j}+\sin 24 \mathrm{H} \times M_{i} \times G_{j}+\cos 12 \mathrm{H} \times M_{i} \times G_{j}+ \\
& \sin 12 \mathrm{H} \times M_{i} \times G_{j}+\text { Animal }_{l}+e_{i j l m} \quad \text { [Model I] }
\end{aligned}
$$

in which BT was hourly body temperature, $\mu$ was average hourly body temperature, $M_{i}$ was the effect of $\mathrm{MG}_{i}, G_{j}$ was the effect of group ${ }_{j}$, and $M_{i} \times G_{j}$ was interaction of $\mathrm{MG}_{i}$ and group ${ }_{j}$. The interaction of $G_{j}$ with $\cos 24 \mathrm{H}$, $\sin 24 \mathrm{H}, \cos 12 \mathrm{H}$, and $\sin 12 \mathrm{H}$ was interaction of group $_{j}$ and trigonometric function periodicities of $24 \mathrm{H}$ and $12 \mathrm{H}$. The interaction of $M_{i}$ and $G_{j}$ with $\cos 24 \mathrm{H}, \sin 24 \mathrm{H}$, $\cos 12 \mathrm{H}$, and $\sin 12 \mathrm{H}$ was interaction of $\mathrm{MG}_{i}$, group ${ }_{j}$, and

\begin{tabular}{|c|c|c|c|c|}
\hline \multirow[b]{2}{*}{ Item } & \multicolumn{4}{|c|}{ Group $^{1}$} \\
\hline & $\mathrm{H} 1$ & $\mathrm{H} 2$ & S1 & $\mathrm{S} 2$ \\
\hline Ambient temperature ${ }^{2},{ }^{\circ} \mathrm{C}$ & $10.2( \pm 7.7)$ & $4.7( \pm 7.0)$ & $-13.9( \pm 6.3)$ & $-8.2( \pm 5.2)$ \\
\hline Relative humidity ${ }^{2}, \%$ & $52.6( \pm 19.7)$ & $81.5( \pm 16.3)$ & $86.0( \pm 7.1)$ & $84.6( \pm 5.5)$ \\
\hline Wind speed ${ }^{2}, \mathrm{~km} / \mathrm{h}$ & $7.8( \pm 4.1)$ & $6.5( \pm 16.3)$ & $7.1( \pm 3.8)$ & $7.9( \pm 4.2)$ \\
\hline Solar Rrdiation ${ }^{2}, \mathrm{kcal} / \mathrm{m} 2 / \mathrm{h}$ & $110.8( \pm 161.1)$ & $58.2( \pm 103.5)$ & $75.6( \pm 120.1)$ & $75.4( \pm 12.52)$ \\
\hline $\mathrm{CCI}^{3},{ }^{\circ} \mathrm{C}$ & $5.4( \pm 8.0)$ & $-0.6( \pm 7.0)$ & $-22.8( \pm 7.2)$ & $-16.8( \pm 5.6)$ \\
\hline Date of cold stress & Nov. 5 to Nov. 9, 2010 & Nov. 21 to Nov. 25,2011 & Jan. 8 to Jan. 12,2010 & Jan. 13 to Jan. 17, 2011 \\
\hline
\end{tabular}
trigonometric function periodicities of $24 \mathrm{H}$ and $12 \mathrm{H}$.

Table 4. Average $( \pm \mathrm{SD})$ environmental conditions, hourly animal body temperature, and dates for each cold stress event by group 
Random effects included animal and a residual (e) with an AR1 covariance structure. The 3-way interaction of $\mathrm{MG}_{\mathrm{i}}$, group $_{j}$, and $12 \mathrm{H}$ trigonometric function periodicity $(P>0.05)$ for summer stress events using Model [I] was not included in the final model.

Covariates of rump fat, BW, and average DMI nested within group were centered to their respective groups and included in Model [I] for winter and summer stress events. The closest rump fat and BW measurement recorded before the temperature related stress period were used in the analysis. The average DMI was the average of DMI during the period or periods of temperature related stress. The interaction of covariate (i.e., rump fat, $\mathrm{BW}$, and average DMI) nested within $\operatorname{group}_{\mathrm{j}}(P>0.05)$ and the 3-way interaction of covariate, $\mathrm{MG}_{i}$, and group ${ }_{j}$ $(P>0.05)$ for the summer and winter stress events were not included in the final model. The effect of pen $(n=2)$ was initially included in Model [I]. The percentages of variation explained by pen for summer and winter stress events were 1.2 and $1 \%$, respectively, and therefore they were not included in the final model. Also, coat color $(P>0.05)$ was not included in the final model. Previous studies (Finch et al., 1984; Davis et al., 2003; BrownBrandl et al., 2006) have found that coat color does have an effect on body temperature, but in our study the distribution of coat colors was heavily weighted toward black. Sex was confounded with group and was therefore not investigated. Body temperature was also analyzed with all groups and stress events combined using the following model:

$$
\begin{aligned}
& \mathrm{BT}_{i j k l m}=\mu+M_{i}+G_{j}+S_{k}+M_{i} \times G_{j} \times S_{k}+\cos 24 \mathrm{H} \times \\
& G_{j} \times S_{k}+\sin 24 \mathrm{H} \times G_{j} \times S_{k}+\cos 12 \mathrm{H} \times G_{j} \times S_{k}+ \\
& \sin 12 \mathrm{H} \times G_{j} \times S_{k}+\cos 24 \mathrm{H} \times M_{i} \times G_{j} \times S_{k}+\sin 24 \mathrm{H} \times \\
& M_{i} \times G_{j} \times S_{k}+\cos 12 \mathrm{H} \times M_{i} \times G_{j} \times S_{k}+\sin 12 \mathrm{H} \times \\
& M_{i} \times G_{j} \times S_{k}+\text { Animal }_{l(k)}+e_{i j k l m} \quad \text { [Model C] }
\end{aligned}
$$

in which BT was hourly body temperature, $\mu$ was average hourly body temperature, $M_{i}$ was the effect of $\mathrm{MG}_{i}, G_{j}$ was the effect of $\operatorname{group}_{j}, S_{k}$ was the effect of season $_{k}$, and $M_{i} \times G_{j} \times S_{k}$ was interaction of $\mathrm{MG}_{i}$, group ${ }_{j}$, and season ${ }_{k}$. The interaction of $G_{j}$ and $S_{k}$ with $\cos 24 \mathrm{H}$, $\sin 24 \mathrm{H}, \cos 12 \mathrm{H}$, and $\sin 12 \mathrm{H}$ was interaction of group ${ }_{j}$, season $_{k}$, and trigonometric function periodicities of $24 \mathrm{H}$ and $12 \mathrm{H}$. The interaction of $M_{i}, G_{j}$, and $S_{k}$ with $\cos 24 \mathrm{H}, \sin 24 \mathrm{H}, \cos 12 \mathrm{H}$, and $\sin 12 \mathrm{H}$ was interaction of $\mathrm{MG}_{i}$, group ${ }_{j}$, season $k$, and trigonometric function periodicities of $24 \mathrm{H}$ and $12 \mathrm{H}$. Random effects include animal nested within season $\mathrm{k}_{\mathrm{k}}$ and a residual (e) with an AR1 covariance structure.

The animal variance divided by the total variance (residual plus animal) was used to estimate the repeatability of hourly body temperature recordings within a season. Least-squares means were estimated for each MG and contrasts were used to estimate additive $[(0$-copy -2 -copy $) / 2]$ and dominance $\{1$-copy $-[(0-$ copy +2 -copy)/2]\} effects.

\section{RESULTS AND DISCUSSION}

Least-squares means by MG along with additive and dominance estimates for Model [C] are presented in Table 5. Model [I] least-squares means and additive and dominance estimates are not shown due to their high degree of similarity with Model [C]. During heat stress conditions, 0-copy animals had higher body temperatures $(P<0.001)$ and were further away from the normal/nonstressed body temperature $\left(38.6^{\circ} \mathrm{C}\right)$ than either 1 - or 2-copy animals. During cold stress conditions, 2-copy animals had lower body temperatures $(P<0.01)$ and were further away from the normal/nonstressed body temperature than either 0 - or 1-copy animals. During summer stress events the additive estimate was $0.10^{\circ} \mathrm{C}(P<0.01)$ and dominance estimate was $-0.12^{\circ} \mathrm{C}(P<0.001)$. During winter stress events the additive estimate was $0.10^{\circ} \mathrm{C}$ $(P<0.001)$ and dominance estimate was $0.054^{\circ} \mathrm{C}(P$ $>0.05)$. Environmental sensitivity for a genotype can

\begin{tabular}{|c|c|c|c|c|c|c|c|c|c|}
\hline \multirow[b]{3}{*}{ Season } & \multicolumn{7}{|c|}{ Myostatin genotype } & \multicolumn{2}{|c|}{ Contrasts } \\
\hline & \multicolumn{2}{|c|}{$\begin{array}{c}0 \text { copies of the inactive } \\
\text { myostatin allele }\end{array}$} & \multicolumn{2}{|c|}{$\begin{array}{l}1 \text { copy of the inactive } \\
\text { myostatin allele }\end{array}$} & \multicolumn{2}{|c|}{$\begin{array}{c}2 \text { copies of the inactive } \\
\text { myostatin allele }\end{array}$} & \multirow[b]{2}{*}{$\mathrm{SE}^{3}$} & & \\
\hline & $n$ & $\mathrm{BT}^{2},{ }^{\circ} \mathrm{C}$ & $n$ & $\mathrm{BT}^{2},{ }^{\circ} \mathrm{C}$ & $n$ & $\mathrm{BT}^{2},{ }^{\circ} \mathrm{C}$ & & $\begin{array}{c}\text { Dominance estimates }{ }^{4} \\
\left( \pm \mathrm{SE} ;{ }^{\circ} \mathrm{C}\right)\end{array}$ & $\begin{array}{c}\text { Additive estimates }{ }^{4} \\
\left( \pm \mathrm{SE} ;{ }^{\circ} \mathrm{C}\right)\end{array}$ \\
\hline Summer & 79 & $39.01^{\mathrm{a}}$ & 93 & $38.79^{b}$ & 53 & $38.81^{\mathrm{b}}$ & 0.03 & $-0.12 \pm 0.03^{*}$ & $0.10 \pm 0.02 * *$ \\
\hline Winter & 77 & $38.47^{\mathrm{a}}$ & 88 & $38.43^{\mathrm{a}}$ & 55 & $38.27^{\mathrm{b}}$ & 0.03 & $0.05 \pm 0.04$ & $0.10 \pm 0.03 * *$ \\
\hline
\end{tabular}
be represented by the slope of a genotypes reaction norm, which graphically displays the effect of different

Table 5. Least-squares means for body temperature by myostatin genotype and season and additive and dominance estimates for Model $\mathrm{C}^{1}$ 

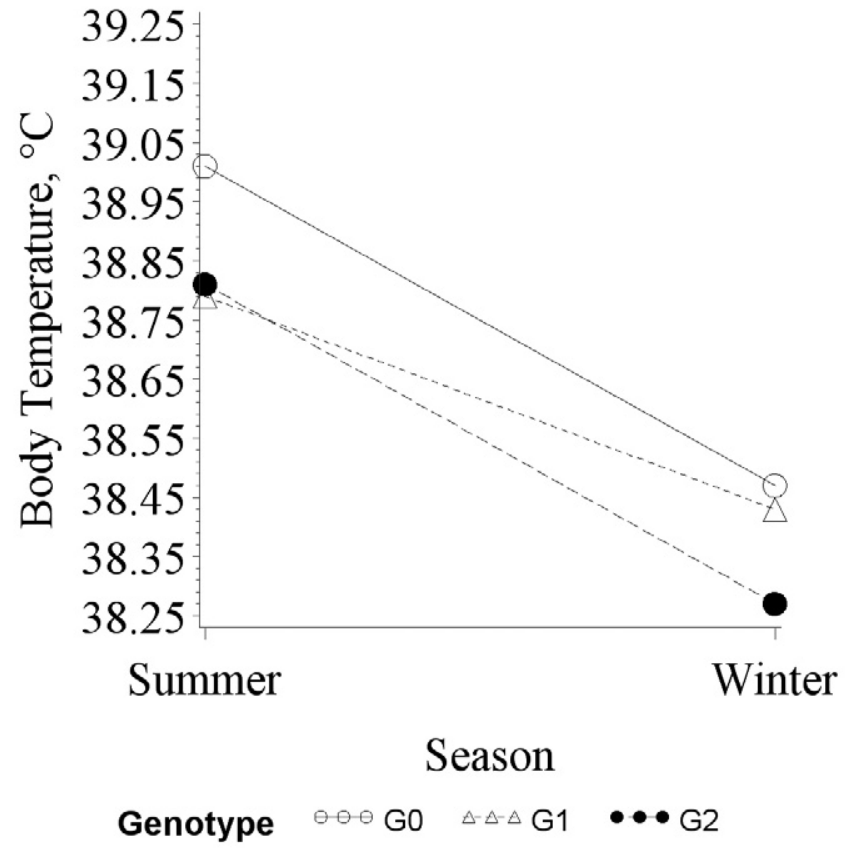

Figure 1. Reaction norm of myostatin genotype during winter and summer conditions. Myostatin genotype refers to animals with 0 copies (G0), 1 copy (G1), or 2 copies (G2) of the inactive myostatin allele.

environments on the average phenotypic value for a genotype, which is illustrated in Fig. 1 (Falconer and Mackay, 1996; De Jong and Bijma, 2002). Figure 1 depicts that the environmental sensitivity differed across genotypes, with 1-copy animals being more robust and 0 - and 2-copy animals being more sensitive to environmental extremes.

The main effect of group $(P<0.001)$ and interaction of group and 24H (cosine $P<0.001$; sine $P<0.001$ ) and $12 \mathrm{H}$ (cosine $P<0.001$; sine $P<0.001$ ) trigonometric function periodicities for Model [I] and the main effect of group $(P<0.001)$, season $(P<0.001)$, and interaction of group and season with $24 \mathrm{H}$ (cosine $P<0.001$; sine $P<0.001)$ and $12 \mathrm{H}($ cosine $P<0.001$; sine $P<0.001)$ trigonometric function periodicities for Model [C] illustrate that the mean body temperature and shape of the diurnal cycle was different across groups and seasons. The difference across groups may be partially explained by the differences in the severity of the stress event that each group experienced. The interactions of group with weight, rump fat, and DMI $(P>0.05)$ illustrate that phenotypic differences across groups for these traits did not have a significant effect on body temperature. The differences across season may partially be due to differences in sunrise and sunset, which impacts the timing at which an animal begins to warm up or cool down due to solar radiation, which had been observed by Lefcourt and Adams $(1996,1998)$.

The main effect of MG $(P<0.01)$ and interaction of MG and group $(P<0.01)$ for Model $[\mathrm{I}]$ and the main effect of MG $(P<0.001)$ and interaction of $M G$, group, and season $(P<0.001)$ for Model [C] show that the mean body temperature varied across MG and this difference varied across groups and season. The interaction of the $24 \mathrm{H}$ trigonometric function periodicity, group, and $\mathrm{MG}$ (cosine $P<0.001$; sine $P<0.001$ ) for summer stress events in Model [I], at least 1 interaction of $24 \mathrm{H}$ (cosine $P<0.02$; sine $P<0.01)$ and $12 \mathrm{H}$ (cosine $P>0.05$; sine $P<0.04)$ trigonometric function periodicities, group, and $\mathrm{MG}$ for winter stress events in Model [I], and at least 1 interaction of $24 \mathrm{H}$ (cosine $P<0.001$; sine $P<0.001)$ and $12 \mathrm{H}$ (cosine $P>0.05$; sine $P<0.02$ ) trigonometric function periodicities, group, season and MG for Model [C] demonstrate that the shape of the diurnal cycle is dependent on $\mathrm{MG}$ and the degree of impact that $\mathrm{MG}$ has on body temperature varied across groups. The varying impact of MG may be partially explained by the varying intensity of heat or cold stress across groups where, under less severe conditions, the variance across animals is smaller, leading to smaller differences in body temperature across MG.

It has been shown that 2-copy animals are substantially leaner than 0-copy animals (Short et al., 2002; Casas et al., 2004) and this same trend was illustrated by Moore et al. (2013) using the same animals as the current study. This lead to the hypothesis that decreased fat cover in 2-copy animals allowed them to remove heat at a faster rate than 0-copy animals during summer and winter conditions. A 3-way interaction of MG and group with either rump fat or BW was not included in the final models $(P>0.05)$, but the main effect of MG $(P<0.05)$ was included in the final models. The insignificant 3-way interaction of $\mathrm{MG}$, group, and rump fat or $\mathrm{BW}$ is most likely attributed to the main effect of MG capturing most of the variation, due to the large differences across MG in rump fat and BW.

Variance components for Models [I] and [C] are presented in Table 6 . The repeatability of hourly body temperature measurements was low to moderate and was within the range of previous internal body temperature repeatability estimates of 0.15 to 0.385 (Seath and Miller, 1947; Turner, 1982, 1984; Burrow, 2001). Environmental variance arises from temporary or localized circumstances, which may have large effects on body temperature. Body temperature differences arise from a complex interaction between anatomical, physiological, and behavioral factors that are dependent on the life stage, nutrition, previous degree of heat or cold stress, and health of the animal (McDowell, 1972; Hahn, 1999).

Modeling of continuous body temperature measurements using a trigonometric function provides an assessment of how a particular genotype responds to heat or cold stress through differences in the intercept and shape of the diurnal cycle. Predicted $24-\mathrm{h}$ cycles by 
Table 6. Variance components $( \pm \mathrm{SE})$ for Models $[\mathrm{I}]$ and $[\mathrm{C}]$

\begin{tabular}{|c|c|c|c|c|c|}
\hline Group $^{1}$ & $\mathrm{Model}^{2}$ & Animal variance & Residual variance & Autoregressive correlation parameter $(\rho)$ & Repeatability $^{3}$ \\
\hline Summer & I & $0.052( \pm 0.006)$ & $0.106( \pm 0.002)$ & $0.79( \pm 0.003)$ & 0.33 \\
\hline Winter & I & $0.073( \pm 0.009)$ & $0.231( \pm 0.004)$ & $0.78( \pm 0.004)$ & 0.24 \\
\hline Combined & $\mathrm{C}$ & $0.063( \pm 0.005)$ & $0.168( \pm 0.002)$ & $0.78( \pm 0.003)$ & 0.27 \\
\hline
\end{tabular}

genotype averaged across group are shown graphically in Fig. 2 and 3 for summer and winter stress events, respectfully. Figure 2 illustrates that as 0 -copy animals warm up during periods of heat stress their slope is steeper and intercept larger than 1- or 2-copy animals, which yields a higher body temperature at the peak of their 24-h body temperature cycle. In contrast, Fig. 3 illustrates that as 2-copy animals cool down during periods of cold stress, their slope is steeper and intercept lower than 0 - or 1-copy animals, which yields a lower body temperature at the trough of their 24-h cycle.

The current study illustrated that a genotype $x$ environment interaction exists for the Piedmontesederived myostatin mutation during periods of heat and cold stress and 1-copy animals were more robust to environmental extremes in comparison with 0 - or 2- copy animals. Breed fraction was unknown due

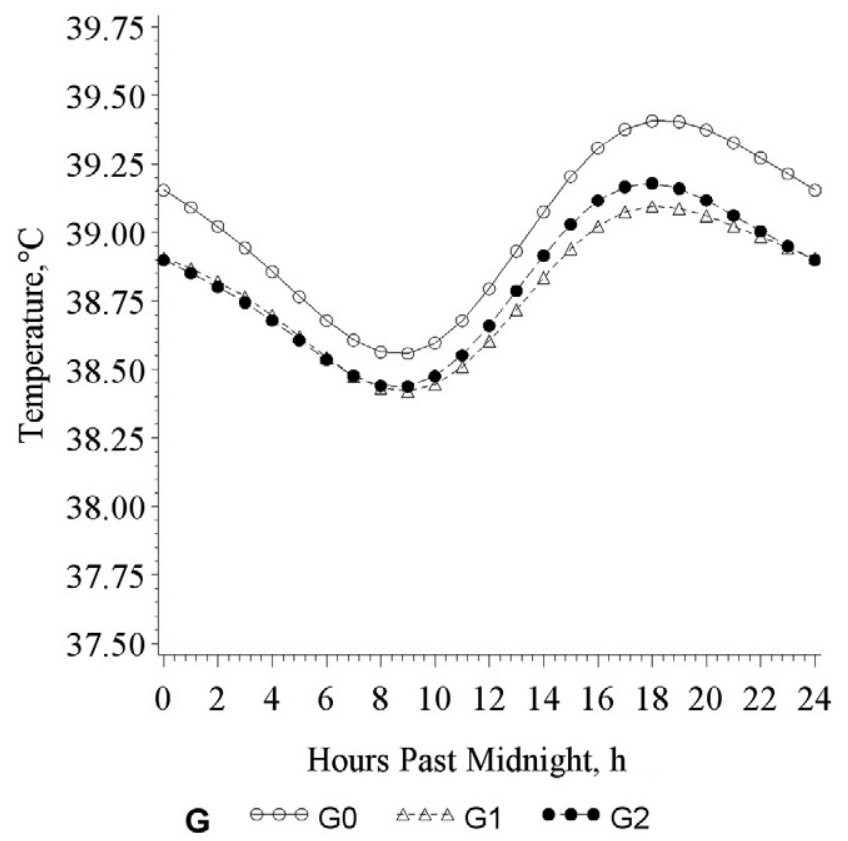

Figure 2. Predicted body temperature averaged across groups by myostatin genotype using a trigonometric function (sine + cosine) model during a 24-h period summer stress event. Myostatin genotype refers to animals with 0 copies (G0), 1 copy (G1), or 2 copies (G2) of the inactive myostatin allele. Hour 0,12 , and 24 correspond to midnight, noon, and midnight of the next day. to a lack of pedigree information and therefore it is possible that MG served as an indicator of breed composition in the current study as 2-copy animals would be hypothesized to have greater Piedmontese influence than 1-copy animals and 1-copy animals would have greater Piedmontese influence than 0 -copy animals. However, the current study illustrated differences in environmental sensitivity between different genetic backgrounds and this knowledge can aid in the management of cattle to ensure optimal performance. This methodology can be transferred to other genetic variants more conducive to mainstream beef production to alleviate the effects of cold or heat stress on production traits. Further work needs to be done to better understand the genetic architecture of body temperature regulation under environmental stress conditions to inform management decisions of beef cattle and the development of marker-assisted management tools.

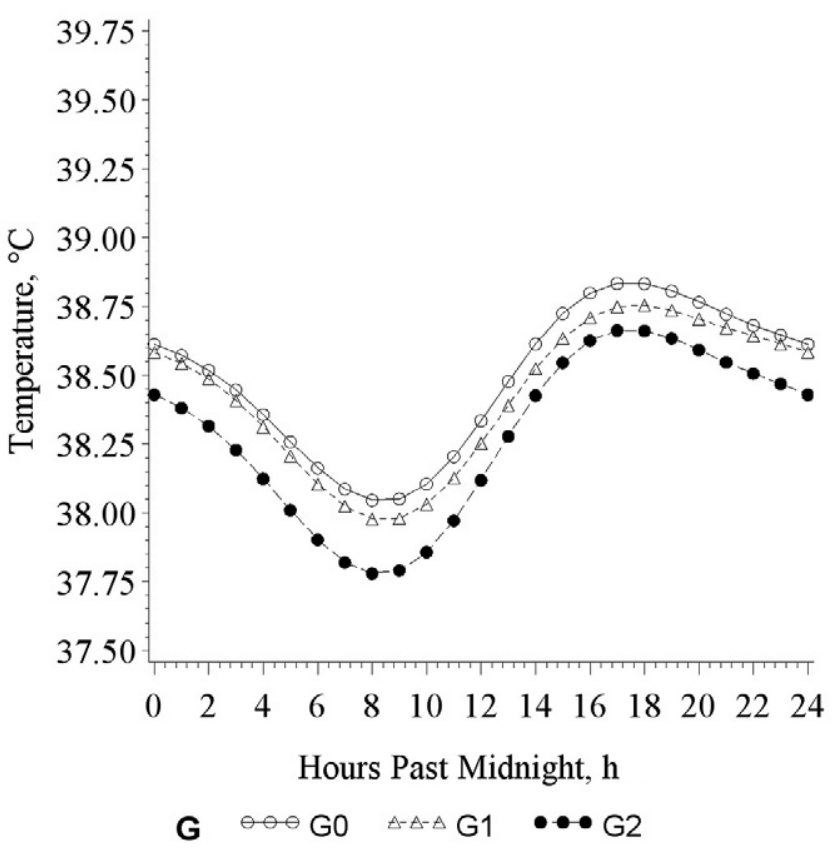

Figure 3. Predicted body temperature averaged across groups by myostatin genotype using a trigonometric function (sine + cosine) model during a 24-h period winter stress event. Myostatin genotype refers to animals with 0 copies (G0), 1 copy (G1), or 2 copies (G2) of the inactive myostatin allele. Hour 0,12 , and 24 correspond to midnight, noon, and midnight of the next day. 


\section{LITERATURE CITED}

Bergen, R. D., and A. D. Kennedy. 2000. Relationship between vaginal and tympanic membrane temperature in beef heifers. Can. J. Anim. Sci. 80:515-518.

Brown-Brandl, T. M., J. A. Nienaber, R. A. Eigenberg, T. L. Mader, J. L. Morrow, and J. W. Dailey. 2006. Comparison of heat tolerance of feedlot heifers of different breeds. Livest. Sci. 105:19-26.

Burrow, H. M. 2001. Variances and covariances between productive and adaptive traits and temperament in a composite breed of tropical beef cattle. Livest. Prod. Sci. 70:213-233.

Casas, E., G. L. Bennett., T. P. L. Smith., and L. V. Cundiff. 2004. Association of myostatin on early calf mortality, growth, and carcass composition traits in crossbred cattle. J. Anim. Sci. 82:2913-2918.

Da Silva, R. G. 1973. Improving tropical beef cattle by simultaneous selection for weight and heat tolerance. J. Agric. Sci. 96:23-28.

Davis, M. S., T. L. Mader, S. M. Holt, and A. M. Parkhurst. 2003. Strategies to reduce feedlot cattle heat stress: Effects on tympanic temperature. J. Anim. Sci. 81:649-661.

De Jong, G., and P. Bijma. 2002. Selection and phenotypic plasticity in evolutionary biology and animal breeding. Livest. Prod. Sci. 78:195-214.

Dikmen, S., J. B. Cole, D. J. Null, and P. J. Hansen. 2012. Heritability of rectal temperature and genetic correlations with production and reproduction traits in dairy cattle. J. Dairy Sci. 95:3401-3405.

Falconer, D. S., and T. F. C. Mackay. 1996. Introduction to quantitative genetics, 4th ed. Longman Scientific and Technical, New York, NY.

Finch, V. A., I. L. Bennett, and C. R. Holmes. 1984. Coat color in cattle: Effect on thermal balance, behavior and growth, and relationship with coat type. J. Agric. Sci. 102:141-147.

Hahn, G. L. 1999. Dynamic responses of cattle to thermal heat loads. J. Anim. Sci. 77:10-20.

Kambadur, R., M. Sharma, T. P. L. Smith, and J. J. Bass. 1997. Mutations in myostatin (GDF8) in double-muscled Belgian Blue and Piedmontese cattle. Genome Res. 7:910-915.

Kaps, M., and W. Lamberson. 2004. Biostatistics for animal science. CABI Pub, Cambridge, MA.

Lefcourt, A. M., and W. R. Adams. 1996. Radiotelemetry measurement of body temperatures of feedlot steers during the summer. J. Anim. Sci. 74:2633-2640.
Lefcourt, A. M., and W. R. Adams. 1998. Radiotelemetry measurement of body temperatures of feedlot steers during the winter. J. Anim. Sci. 76:1830-1837.

Littell, R. C., P. R. Henry, and C. B. Ammerman. 1998. Statistical analysis of repeated measures data using SAS procedures. J. Anim. Sci. 76:1216-1231.

Mader, T. L., S. M. Davis, and W. M. Kreikemeier. 2005. Case study: Tympanic temperature and behavior associated with moving feedlot cattle. Prof. Anim. Sci. 21:339-344.

Mader, T. L., L. J. Johnson, and J. B. Gaughan. 2010. A comprehensive index for assessing environmental stress in animals. J. Anim. Sci. 88:2153-2165.

McDowell, R. E. 1972. Improvement of livestock production in warm climates. W. H. Freeman, San Francisco, CA.

McGee, D. A., R. J. Rasby, M. K. Nielsen, and T. L. Mader. 2008. Effects of summer climate conditions on body temperature in beef cows. Pages 13-15 in Nebraska Beef Cattle Report MP91. University of Nebraska, Lincoln.

Moore, S. K., C. J. Schneider, K. M. Rolfe, B. L. Nuttelman, D. B. Burken, W. A. Griffin, J. R. Benton, G. E. Erickson, and M. L. Spangler. 2013. Association of Inactive Myostatin in Piedmontese-Influenced Steers and Heifers on Performance and Carcass Traits at Different Endpoints. Pages 53-55 in Nebraska Beef Cattle Report MP98. University of Nebraska, Lincoln.

NRC. 1996. Nutrient requirements of beef cattle. National Academy Press, Washington, D.C.

Ravagnolo, O., and I. Misztal. 2000. Genetic component of heat stress in dairy cattle, parameter estimation. J. Dairy Sci. $83: 2126-2130$.

Ravagnolo, O., and I. Misztal. 2002. Effect of heat stress on nonreturn rate in Holstein cows: Genetic analyses. J. Dairy Sci. 85:3092-3100.

Seath, D. M., and G. D. Miller. 1947. Repeatability of heat tolerance observations. J. Dairy Sci. 30:957-962.

Short, R. E., M. D. MacNeil, M. D. Grosz, D. E. Gerrard, and E. E. Grings. 2002. Pleiotropic effects in Hereford, Limousin, and Piedmontese $\mathrm{F}_{2}$ crossbred calves of genes controlling muscularity including the Piedmontese myostatin allele. J. Anim. Sci. 80:1-11.

Turner, H. G. 1982. Genetic variation of rectal temperature in cows and its relationship to fertility. Anim. Prod. 35:401-412.

Turner, H. G. 1984. Variation in rectal temperature of cattle in a tropical environment and its relation to growth rate. Anim. Prod. 38:417-427.

Young, B. A. 1983. Cold stress as it affects animal production. J. Anim. Sci. 52:154-163. 